\title{
LA TRAMPA DE LA FÁBRICA EN FABIÁN Y EL CAOS DE PEDRO JUAN GUTIÉRREZ
}

\author{
THE TRAP OF THE FACTORY IN FABIÁN Y EL CAOS \\ OF PEDRO JUAN GUTIÉRREZ
}

\author{
María Elena Esparza Pezo ${ }^{1}$ \\ Universidad de Concepción \\ Chile \\ mariaelenesparz@udec.cl
}

\begin{abstract}
Resumen: El artículo examina la fábrica como espacio diegético en la novela Fabián y el caos de Pedro Juan Gutiérrez. Considerando los planteamientos teóricos de Roland Barthes, Philippe Hamon, Luz A. Pimentel, Antonio Garrido y Janusz Slawinski, se evidencia la representación de este espacio como un lugar de castigo y corrupción, según la perspectiva de cada uno de sus protagonistas. El análisis se centra en la representación novelesca de los primeros años de la Revolución cubana y su forma de disciplinar a los homosexuales y quienes están al margen del hombre nuevo.
\end{abstract}

Palabras clave: Revolución cubana - homosexualidad - espacio diegético - corrección.

\begin{abstract}
The article examines the factory as a diegetic space in the novel Fabián $y$ el caos by Pedro Juan Gutiérrez. Considering the theoretical approaches of Roland Barthes, Philippe Hamon, Luz A. Pimentel, Antonio Garrido and Janusz Slawinski, the representation of this space as a place of punishment and corruption gets evident, according to the perspective of each of its protagonists. The analysis focuses on the fictional representation of the first years of the Cuban Revolution and its way of disciplining homosexuals and those who are on the fringes of the new man.
\end{abstract}

Keywords: Cuban revolution - homosexuality - diegetic space - correction.

Recibido: 16/10/2020. Aceptado: 04/12/2020.

${ }^{1}$ Candidata a Dr. en Literatura Latinoamericana de la Universidad de Concepción. Este artículo forma parte de la tesis doctoral "Valores del espacio diegético y su relación con el poder en Fabián y el caos de Pedro Juan Gutiérrez y Tengo miedo torero de Pedro Lemebel” dirigida por el profesor Mario Rodríguez y desarrollada mediante Beca Conicyt. 


\section{Introducción}

"Creo profundamente en el papel del escritor como la conciencia alerta y crítica de la sociedad."

(Pedro Juan Gutiérrez)

$F$ abián y el caos (2015) de Pedro Juan Gutiérrez es una novela basada en hechos reales ${ }^{2}$ y está centrada en Cuba después del triunfo de la Revolución. Narra la vida de Fabián, un joven pianista homosexual, y Pedro Juan, el conocido personaje de la obra narrativa del escritor cubano. Ambos personajes, al escapar del modelo del joven revolucionario que propugna el régimen político instaurado por la Revolución, son enviados a trabajar a una fábrica de carne enlatada para corregir sus respectivas conductas.

La novela está estructurada en cinco capítulos de los que tres corresponden al relato de la historia de Fabián, el protagonista. Estos capítulos, específicamente el 1, 3 y 5, están relatados por un narrador omnisciente, en tercera persona. El resto de los capítulos, vale decir, el 2 y 4, pertenecen al relato en primera persona de Pedro Juan, protagonista de otros relatos del escritor como Trilogía sucia de La Habana (1998) y El nido de la serpiente. Memorias del hijo del heladero (2006).

Al ser consultado por el periodista Carlos Olivares Baró, sobre el uso de dos personas narrativas en la novela, Pedro Juan Gutiérrez declaró:

Me di cuenta que la crónica de las alternativas de Fabián y de sus padres _Felipe y Lucía_necesitaba cierta objetividad. Recurro entonces a un narrador que lo ve todo, que lo sabe todo, para describir la llegada de España a Matanzas de los progenitores de Fabián en los años prerrevolucionarios, el arribo de Fidel Castro al poder y la radicalización de la Revolución en los años 60 y 70. Sin embargo, los incidentes de Pedro Juan están contados en primera persona porque están delineados desde la subjetividad: gestos intrínsecos de un desadaptado, quien rutinariamente sigue el curso de los acontecimientos de aquellos años cincelados en escenarios naufragantes. Más que un contraste, yo diría que es un

\footnotetext{
${ }^{2}$ Pedro Juan Gutiérrez señaló en una entrevista con el diario español El Mundo (2015) que estuvo "21 años pensando si debía escribir esta novela por una cuestión ética, porque me molestaba aprovecharme de la historia de un amigo". El amigo es Fabio Hernández a quien está dedicada la novela.
} 
mismo narrador desplegado en dos gestos, en dos perspectivas, en dos visiones e incluso en dos consumaciones existenciales.

La presencia de los dos narradores o del mismo narrador desplegado en dos gestos como afirma el escritor cubano, cumple funciones bastante específicas en el relato, aspecto que desarrollaremos más adelante.

Luz Aurora Pimentel asevera que describir es "adoptar una actitud frente al mundo" (2001, p. 16) y el narrador de la novela que estamos analizando presenta una actitud crítica frente al proceso revolucionario que se vivió en la isla debido a que este periodo histórico es representado desde una perspectiva irónica, ya que afirma que nadie vio "la trampa" que le habían tendido al pueblo cubano, recurriendo a un intertexto con los cómics:

En ese momento todos los cubanos, seis millones de personas, quedaron igualados por lo bajo. Como un golpe de kárate. Magistral. En un instante dejaron de existir la clase alta, la media y la baja. Mandrake el Mago, con un solo pase de sus manos, hizo un truco perfecto delante de los ojos de todos, y nadie vio la trampa. Ahora todos eran pobres de verdad. En todos los sentidos. No solo económicamente. Era un golpe genial, algo perfecto. Pero era solo el comienzo. Lo mejor vendría después. ${ }^{3}$ (p. 51)

En el fragmento hay un detalle o catálisis (Barthes) que adquiere máxima importancia. Nos referiremos al concepto de trampa que introduce significados como: "Contravención disimulada de una ley, convención o regla, o manera de eludirla con miras al provecho propio" y "ardid para burlar o perjudicar a alguien” (DRAE). Los semas presentes en ambas definiciones poseen connotaciones negativas, pues remiten a engaño, farsa, maquinación, entre otras. Este detalle cobra plena relevancia, debido a que introduce al lector en una historia que tendrá una perspectiva crítica de la revolución cubana, aspecto que está presente tanto en el relato de la historia de Fabián como en la narración de Pedro Juan. Así, ambas historias escenifican los abusos de poder que se llevaron a cabo a partir de la instauración del régimen político que comenzaron a vivir miles de cubanos, sin embargo, la novela representa a través de la ficción lo que ocurre a quienes,

\footnotetext{
3 Pedro Juan Gutiérrez. 2015. Fabián y el caos. Barcelona: Anagrama. Los énfasis son nuestros. En adelante citaremos solo indicando el número de página.
} 
de una u otra forma, no cumplen con los requisitos necesarios que establece el proyecto revolucionario. Asimismo, en el fragmento transcrito es posible establecer las siguientes conexiones: en primer lugar, una relación provocativa y mordaz entre Fidel Castro, líder de la Revolución cubana, y Mandrake el Mago, dado que se establece una analogía entre el líder de la revolución y el famoso ilusionista. En segundo lugar, la Revolución es presentada como trampa:

Fidel Castro = Mandrake el Mago

Revolución $=$ Trampa

Así, este hecho histórico es ironizado y se denuncia como un evento basado en un engaño que trae consecuencias nefastas porque "ahora todos eran pobres de verdad”. La otra afirmación del narrador "Lo mejor vendría después" también posee un tono irónico y se opone de manera radical a los acontecimientos narrados, pues el relato evidencia que después del triunfo revolucionario hay una serie de cambios que afectan de manera perjudicial a la sociedad cubana representada en la novela.

En efecto, las descripciones de Cuba después del triunfo de la Revolución se distinguen por la presencia de semas que demuestran esta radical transformación social desde una perspectiva crítica, debido a que el país es representado como un espacio dominado por lo caótico e incomprensible:

Felipe no sabía qué hacer. Lo sentía todo como un remolino indetenible. El país de pronto se convirtió en una vorágine ruidosa y caótica, imprevisible, incansable, que arrastraba a todos, como un huracán inmenso y total, que se tragaba todo lo que se interponía en su camino (p. 47)

El fragmento transcrito representa a la Revolución con sustantivos como "remolino", "vorágine” y "huracán", los que hacen referencia a aspectos negativos, especialmente el término huracán que introduce semas relacionados con "suceso o acontecimiento que causa destrucciones o grandes males” (DRAE). Además, el proceso revolucionario adquiere ribetes de

\footnotetext{
${ }^{4}$ El énfasis es nuestro.
} 
monstruosidad debido a que en la descripción se afirma que "se tragaba todo". Por su parte, el término remolino remite a "amontonamiento de gente, o confusión de unas personas con otras, por efecto del desorden" y además significa “disturbio, inquietud, alteración” (DRAE). Vorágine, por otro lado, contiene semas que también dan cuenta de una situación en que predomina la confusión y el desorden: "Aglomeración confusa de sucesos, de gentes o de cosas en movimiento”.

En la descripción podemos reconocer el concepto de operadores tonales planteado por Pimentel (2001, p. 27) porque todos los adjetivos y frases que califican a la Revolución la representan de manera perjudicial, monstruosa, caótica. La reiteración de los mismos elementos va formando un campo semántico donde se encuentran presentes los valores ideológicos del texto. En este caso todos estos elementos destacan por su connotación negativa, así el gran cambio social que vive el país es delineado como dañino, caótico y confuso. En consecuencia, la significación ideológica de la descripción se proyecta al resto de la narración y va a estar presente de manera destacada y dominante en toda la novela.

Una novela que cuestiona y erosiona el poder como lo hace Fabián y el caos, nos hace preguntarnos por la posición estética y política del escritor cubano. Pedro Juan Gutiérrez afirmó en una entrevista del año 2012 que la esencia de su posición estética es "tratar de decir lo que la gente no quiere oír, lo que la gente no quiere ver.” Y en una entrevista del año 2015 dijo que: "En cualquier sociedad y cualquier época hay una serie de convenciones y las instituciones de poder tratan de mantener a todo el mundo dentro de esas convenciones". Por tal razón, señala que la función del escritor "es precisamente romper la frontera del silencio". Asimismo, reconoce que casi todos sus libros van "dejando una memoria de una época, un tiempo" y, efectivamente, con Fabián y el caos ingresamos a una época marcada por la intolerancia, la rigidez y la violencia.

El escritor cubano ha reflexionado sobre la relación entre literatura y poder en su ensayo "Verdad y mentira en la literatura" (2001), en el que expone el efecto que la buena literatura puede ocasionar entre quienes ejercen el poder. $\mathrm{Al}$ respecto afirma que:

La buena literatura habitualmente molesta a los poderes establecidos, ya que revela a los seres humanos en su doble faceta de luz y tinieblas, 
amor y odio. Revelar eso entorpece la manipulación embrutecedora de los ejes del poder que prefieren rebaños de pueblos mansos, fanatizados por algunas ideas simplistas. El pensamiento implacable, profundo y libre, interrumpe sus planes de adoctrinamiento y estupidización. Prefieren dirigir rebaños de corderos ciegos y semianalfabetos. Es mucho más fácil y cómodo. $\left(2001 \mathrm{~s} / \mathrm{n}^{0}\right)$

Tanto el relato de Fabián como el de Pedro Juan presentan una imagen tremendamente negativa de la Revolución cubana, lo que nos permite postular que Fabián y el caos es una novela de denuncia política debido a que evidencia, por una parte, la relación conflictiva entre Revolución y homosexualidad y, por otra, expone la corrupción del poder, apartándose así de la perspectiva heroica presente en la historia oficial.

\section{Contexto histórico: Revolución y homosexualidad}

Antes de examinar las descripciones de la fábrica es necesario tener en cuenta el contexto histórico representado en la novela con el propósito de tener una visión más completa de la situación que afecta a los homosexuales después del triunfo de la Revolución.

Sobre el periodo histórico en que está centrada su novela, Pedro Juan Gutiérrez comenta en una entrevista con el diario español El Mundo (2015) que:

La Cuba de los 60 y 70 fue muy peculiar: por un lado, muy heroica, pero también violenta y opresiva. Los homosexuales eran apartados del arte y la cultura, que tenían que estar al servicio del pueblo, porque decían que ellos no reunían las condiciones necesarias, y los destinaban a las UMAP (Unidades Militares de Apoyo a la Producción). A mi amigo no lo enviaron a cortar caña, pero sí a una fábrica horrorosa en la que nos reencontramos.

Efectivamente, la novela está centrada en un período violento y opresivo que no solo afectó de manera perjudicial a los homosexuales, sino también a todos aquellos que eran considerados "lacras sociales" dentro del contexto revolucionario.

Según Óscar Contardo, el discurso oficial del nuevo régimen fue tajante 
desde un principio: "Fidel Castro sostenía que la homosexualidad era un vicio burgués, ajeno a la virilidad natural del trabajador isleño y, por tanto, una amenaza para el régimen" (Contardo, 2012, p. 254). El líder cubano se refirió a los homosexuales en varias ocasiones y una de ellas fue el Discurso de Clausura del Acto para conmemorar el VI aniversario del asalto al Palacio Presidencial, que fue celebrado en la escalinata de la Universidad de la Habana, el 13 de marzo de 1963. En esta ocasión afirmó:

Porque, señores, no se olviden de esto, sobre todo ustedes, jóvenes ... la contrarrevolución aglutina a lo peor, desde el burgués hasta el mariguanero, desde el esbirro hasta el ratero, desde el dueño de central hasta el vago profesional, el vicioso; y todo ese elemento se junta para dar batalla a la ley, y a la Revolución, a la sociedad, para vivir de vagos, para estorbar. Todo, lo peor, se junta [...] Muchos de esos pepillos ${ }^{5}$ vagos, hijos de burgueses, andan por ahí con unos pantaloncitos demasiado estrechos (RISAS); algunos de ellos con guitarra en actitudes "elvispreslianas", y que han llevado su libertinaje a extremos de querer ir a algunos sitios de concurrencia pública a organizar sus shows feminoides por la libre. Que no confundan la serenidad de la Revolución y la ecuanimidad de la Revolución con debilidades de la Revolución. Porque nuestra sociedad no puede darles cabida a esas degeneraciones (APLAUSOS). La sociedad socialista no puede permitir este tipo de degeneraciones ${ }^{6}$.

El investigador afirma que en este sentido la Revolución cubana "coincidía totalmente con el gobierno norteamericano, que desde la década del cincuenta había adoptado una política explícita que marginaba a los ho-

\footnotetext{
${ }^{5}$ Abel Sierra Madero afirma que en 1928 se inició en Cuba una de las campañas públicas más acerbas durante la época republicana. Desde el periódico La Semana y la revista Carteles, los periodistas Sergio Garbó y Mariblanca Sabas Alomá, respectivamente, se pronunciaron en contra de dos vertientes sociales de índole sexual: el pepillismo y el garzonismo, que se convirtieron en fenómenos políticos. El investigador señala que Sergio Garbó "fabricó el pepillito, que entonces adquirió una connotación semántica peyorativa y se convirtió en el máximo insulto que podían soportar la dignidad y el honor masculinos. Los pepillos fueron asediados y perseguidos en nombre de la moral y de las buenas costumbres, pero sobre todo, en nombre de la nación". (2006, pp. 81-82).

${ }^{6}$ Cinco décadas después del triunfo revolucionario, Fidel Castro ha asumido su responsabilidad por la intensa persecución que llevó a cabo su gobierno en contra de los homosexuales, a quienes acusó de ser unos "contrarrevolucionarios." Al ser consultado quién fue el responsable de esta situación, afirmó en una entrevista con el diario mexicano $L a$ Jornada, que "Si alguien es responsable, soy yo."
} 
mosexuales de cualquier puesto gubernamental 7 " (Contardo, 2012, p. 254). Además, inserta el testimonio del artista chileno Hugo Marín, quien al viajar de manera continua a la isla, conoció de cerca las políticas represivas en contra de los homosexuales. $\mathrm{Al}$ respecto sostiene que:

Los hombres homosexuales no podían trabajar salvo en labores de reeducación que consistían en sembrar malanga y cortar caña. En la revista cultural El Caimán Barbudo, dedicada a la juventud comunista, publicaban caricaturas de las juventudes revolucionarias pateando a los intelectuales homosexuales. (Contardo, 2012, p. 253)

Por su parte, Ambrosio Fornet señala en su ensayo titulado "El Quinquenio Gris: Revisitando el término” que sobre los homosexuales

no pesaban únicamente sospechas políticas, sino también certidumbres científicas, salidas tal vez de algún manual positivista de finales del siglo XIX o de algún precepto de la Revolución Cultural china: la homosexualidad era una enfermedad contagiosa, una especie de lepra incubada en el seno de las sociedades clasistas, cuya propagación había que tratar de impedir evitando el contacto - no sólo físico, sino inclusive espiritualdel apestado con los sectores más vulnerables (los jóvenes en este caso). (Fornet, 2015, p. 220)

Sobre este mismo tema, el historiador cubano Abel Sierra Madero afirma que durante la etapa de agitación revolucionaria, "se pensó que la homosexualidad tenía que ver con algunos males heredados de la sociedad republicana, y que podía reeducarse o anularse mediante el trabajo político, ideológico y, a la vez, productivo" (Sierra, 2006, p. 197). El investigador señala que la homosexualidad "se insertó en el debate nacional como un elemento recurrente y contrastante con el hombre nuevo", planteado por Ernesto Che Guevara en 1965. Al respecto, sostiene que el hombre nuevo "fue el soporte simbólico-discursivo para establecer la nueva ciudadanía

\footnotetext{
${ }^{7}$ Óscar Contardo señala que "un informe del Congreso de Estados Unidos de 1950 concluyó que los homosexuales que trabajaban en los servicios públicos eran un peligro para la seguridad del Estado: se trataba de personas enfermas, susceptibles de ser chantajeadas por agentes extranjeros. A raíz del informe, el Gobierno prohibió el ingreso de homosexuales a la administración pública” (2012, p. 224).
} 
revolucionaria” y que pasó “a ser el referente cultural autóctono y el ideal imaginario de la masculinidad nacional en esta etapa de efervescencia y necesidades históricas aplazadas durante mucho tiempo" (Sierra, 2006, p. 200). El riguroso investigador ha seguido profundizando en este tema y en un artículo titulado "El trabajo os hará hombres": Masculinización nacional, trabajo forzado y control social en Cuba durante los años sesenta”, afirma que

se estableció una conjunción entre nacionalismo y heteronormatividad y se instituyeron una serie de nociones que definieron la ciudadanía, no como un estatus conformado de antemano por un conjunto de derechos, sino como una obligación, una identidad ideal basada en una serie de atributos. Así, aquellos sujetos con configuraciones de género y prácticas sexuales no normativas comenzaron a ser percibidos como enemigos políticos dentro del proyecto revolucionario. (Sierra Madero, 2016, p. 315)

Inmaculada Álvarez coincide con los planteamientos de Abel Sierra Madero y afirma que un rasgo que singularizó a la Revolución fue el explícito rechazo a la homosexualidad, entendida "como símbolo de debilidad que alejaba lo masculino del ideal militar revolucionario" (Álvarez, 2003, p. 25). Plantea que la Revolución unió el proyecto político y económico al de regeneración social de la Isla. En este sentido, sostiene que las autoridades revolucionarias del régimen estaban convencidas de que tanto la homosexualidad como la prostitución eran consecuencia de la "degeneración de la burguesía fascista de Batista” (Álvarez, 2003, p. 27). La investigadora

\footnotetext{
${ }^{8}$ Inmaculada Álvarez señala que en 1889 el Diccionario razonado de legislación para la policía de La Habana define la palabra "maricón" como "hombre afeminado y cobarde" y afirma que la identificación entre homosexualidad y cobardía "sirve para situar en la marginalidad todo aquello que se aparte del modelo ideal masculino" (2003, p. 18) cuyo referente es el "valiente héroe militar" del imaginario surgido tras las guerras de independencia. La investigadora plantea que José Martí escribe variados textos periodísticos como "Do we want Cuba? (1889) y tanto en este artículo como en otros aparece el concepto de hombre afeminado "asociado a inferioridad social y debilidad, mientras lo fuerte y viril se considera símbolo de las naciones modernas y desarrolladas" (2003, p. 19). Plantea que en el ensayo Nuestra América, Martí construye su concepto de "hombre natural" como "modelo de ideal masculino nuevamente en oposición al hombre afeminado a quien considera consecuencia del materialismo moderno" (2003, p. 19). Álvarez afirma que Martí establece de esta forma, un modelo ideal de cubano rechazando toda orientación sexual considerada como "no natural".
} 
señala que a partir del triunfo de la Revolución, la figura de Fidel Castro y de los más destacados héroes de la Revolución como Ernesto Che Guevara o Camilo Cienfuegos, "representan para Cuba el personaje de referencia, la autoridad estatal del héroe revolucionario que perpetúa en el imaginario el poder patriarcal" (Álvarez, 2003, p. 29). Sostiene que el modelo masculino viril del héroe revolucionario favoreció la extensión del sentimiento homofóbico.

\section{Fabián y la fábrica}

La novela Fabián y el caos está centrada en este contexto adverso para las minorías sexuales. Cabe destacar que no es la primera vez que Pedro Juan Gutiérrez incorpora en su producción narrativa a personajes homosexuales ${ }^{9}$. De hecho, en El nido de la serpiente. Memorias del hijo del heladero (2006) también se refiere a ellos y a la represión que debieron enfrentar tras la instauración del régimen revolucionario.

En la mencionada novela, Pedro Juan afirma que "tampoco se podía andar pelú y con los pantalones apretados. Eso era cosa de maricones. Y ser maricón también era desviación ideológica. Había que ser macho y demostrarlo" (p. 36). El narrador también hace referencia a Gretel, una amiga, que fue expulsada de la universidad por tener una relación con una compañera. Esta decisión provoca una ruptura familiar, debido a que su padre también la rechaza: "Que ya no era mi padre, porque yo era una tortillera de mierda y una gusana con cincuenta desviaciones ideológicas” (pp. 168169). Además, relata el caso de Genovevo, homosexual conocido como la Señora. Este singular personaje, que está a cargo del cuidado de la mansión de sus patrones en la ciudad de Varadero, se caracteriza por salir en las noches vestido de mujer. Esta transgresión provoca el temor de una de las empleadas de la residencia a raíz de los castigos a que eran sometidos quienes infringían las estrictas normas de comportamiento impuestas por las autoridades revolucionarias. Específicamente se refiere a las Unidades

${ }^{9}$ En Trilogía sucia de La Habana hay un relato denominado "Maricón y suicida" en el que aparece un personaje homosexual, sin embargo, está situado en el denominado "Periodo Especial”, contexto muy distinto al que se narra en la novela Fabián y el caos. 
Militares de Ayuda a la Producción ${ }^{10}$ porque si "lo cogen preso, lo meten en una UMAP y no se sabe cuándo lo van a soltar. Es un riesgo muy grande" (p. 179).

De los fragmentos transcritos podemos concluir que la novela El nido de la serpiente. Memorias del hijo del heladero es un relato en el que se hacen referencias explícitas a las consecuencias que debían enfrentar quienes tuvieran otra orientación sexual y se apartaran de los parámetros que regían la nueva sociedad surgida tras el triunfo de la Revolución. En este contexto, la novela muestra los castigos que recibían aquellos que infringían las normas como la expulsión de la universidad, en el caso de Gretel, o el envío a las UMAP como le podría haber sucedido a Genovevo.

La ilusión de realidad de la novela Fabián y el caos se construye en torno al nombre propio, ya que las acciones están situadas en Matanzas y desde el punto de vista histórico narra las condiciones desfavorables y hostiles que debieron enfrentar los homosexuales, sin embargo, profundiza aún más en el contexto a través de la historia de Fabián. Tanto el relato de Fabián como el de Pedro Juan contienen una serie de descripciones sobre la fábrica, lugar al que ambos fueron enviados por orden de las autoridades revolucionarias. En este sentido, es pertinente considerar los planteamientos teóricos de Antonio Garrido y Janusz Slawinski sobre el espacio. El investigador español afirma que "lo habitual es que cada personaje tenga asignada una determinada parcela de ese espacio de un modo muy preciso" (Garrido, 1996, p. 217) y el teórico polaco sostiene que a un personaje determinado "se le atribuye cierto repertorio de territorios en los que puede aparecer” (Slawinski, 1989 p. 14). Ambos personajes, Fabián y Pedro Juan, están situados en la misma parcela, es decir, en la fábrica y cada una de sus respectivas visiones, al estar situados en un mismo "territorio", contribuyen a tener una perspectiva más amplia y completa de este espacio.

El narrador afirma que a Fabián "lo jodieron por maricón" (p. 211), vale

${ }^{10}$ Abel Sierra Madero afirma que el emplazamiento de las UMAP se realizó a fines de 1965 y señala que estas unidades "se crearon bajo la cobertura de la ley 1129 del 26 de noviembre de 1963 que estableció el Servicio Militar Obligatorio durante un periodo de tres años para los hombres comprendidos en las edades entre dieciséis y cuarenta y cinco años" (2016, p. 322). El historiador cubano plantea que a las UMAP no solo eran enviados los homosexuales, "sino otros sujetos como delincuentes, religiosos, intelectuales o simplemente muchachos cautivados por el movimiento hippie norteamericano" (2016, p. 316). 
decir, que las autoridades revolucionarias lo desvincularon de su trabajo en el Teatro de Ópera exclusivamente por su condición sexual. Los siguientes fragmentos evidencian este aspecto tanto en un capítulo que narra la historia de Fabián como en un capítulo narrado por Pedro Juan, en el que Fabián le cuenta a su ex compañero cómo llegó a trabajar a la fábrica:

Cuando Fabián fue separado del Teatro Ópera todos sabían el motivo. El chisme se regó de inmediato porque la parametración ${ }^{11}$ sólo afectó a Fabián y a dos jovencitos bailarines que hacían alarde de su encantadora femineidad. Muy simpáticos y alegres. También fueron enviados a alguna fábrica. $\mathrm{Y}$ desaparecieron en el paisaje. El otro pianista, un viejo muy maricón y mala pécora, logró salvarse ... Así que inmediatamente todos negaron el saludo a Fabián y hasta dejaron de mencionarlo en sus conversaciones. Lo pusieron a un lado del grupo. Tenían miedo de que los llamaran de la famosa "Comisión técnica" y los expulsaran también. Era lógico. Siempre es así. La gente quiere salvar su pellejo. Sólo Manolo siguió visitando su casa, aunque aumentó más aún la discreción. Nadie quería ser amigo de un maricón (p. 211)

Mira, yo estudiaba en el conservatorio y me dieron una plaza de pianista acompañante, en el teatro, en la Compañía de Ópera. Y las cosas iban bien. Estuve en eso tres años y pico. Un día, hace dos meses más o menos, me llamaron a la oficina del director. Había un grupito allí de tres o cuatro jefes. Tú sabes, el del sindicato, el del partido, el director artístico, el del municipio, qué sé yo. Todos muy machitos. Se esforzaban en poner la voz gorda y la cara muy seria. Me dijeron que la comisión técnica había decidido que yo no cumplía los parámetros para trabajar en cultura y que a partir de ese momento prescindían de mis servicios. Me quedé paralizado. Y se me ocurrió pedirles que me explicaran. Si eran parámetros técnicos. Entonces me leyeron unos párrafos de un acta que

${ }^{11}$ Reinaldo Arenas en su autobiografía Antes que anochezca comenta que la parametración también afectaba a mujeres solteras que tenían "una vida sexual un poco liberal". Afirma que en este período "se hicieron famosas las recogidas de mujeres en las posadas. Estas posadas eran lugares creados por la Revolución donde las personas heterosexuales podían entrar unas horas y hacer el amor. La policía, sin embargo, entraba en aquellas posadas para ver qué mujeres cometían adulterio y, sobre todo, si eran las esposas de algún militante del Partido Comunista. Las mujeres sufrían castigos y eran incluso separadas de su trabajo, y sus maridos eran informados inmediatamente en una asamblea pública. De manera que la mujer, como el homosexual, son considerados en el sistema castrista como seres inferiores. Los machos podían tener varias mujeres y esto se veía como un acto de virilidad. De ahí que las mujeres y los homosexuales se unieran, aunque sólo fuera como una manera de protegerse.” (R. Arenas, 2010, pp. 177-178) 
habían levantado. Ponía que mis gustos sexuales son una aberración y mi actitud ante la sociedad es muy negativa, que soy un mal ejemplo y con una posición enfrentada a la revolución y que por tanto me ponían a disposición del Ministerio del Trabajo para que me asignara una plaza en otro sector, ya que la cultura está al servicio del pueblo y es inadmisible que trabajen personas desafectas, etcétera, etcétera (pp. 191-192)

Según Ambrosio Fornet, este procedimiento se llamó depuración o "parametración" (Fornet, 2015, p. 220) y fue aplicado especialmente en los sectores laborales considerados de alto riesgo como lo eran el magisterio y, sobre todo, el teatro, las artes escénicas en general porque:

Se había llegado a la conclusión de que la simple influencia del maestro, el actor o bailarín sobre el alumno o el espectador adolescente podía resultar riesgosa, lo que explica en una comisión del Congreso de Educación y Cultura, al abordar el tema de la influencia del medio social sobre la educación, se dictaminara que no era "permisible que por medio de la calidad artística reconocidos homosexuales ganen prestigio que influye en la formación de nuestra juventud”. (Fornet, 2015, p. 220)

El ensayista cubano afirma que por tales razones en los centros dedicados a la docencia o el teatro, "los trabajadores que no respondieran a las exigencias o "parámetros" que los calificaran como individuos confiables, es decir, revolucionarios y heterosexuales, serían reubicados en otros centros de trabajo" (Fornet, 2015, p. 220). ${ }^{12}$ Plantea que algunos artistas e intelectuales fueron simplemente "castigados por sus desviaciones ideológicas, las que se corregían trabajando duro en la agricultura o en una fábrica” (Fornet, 2015, p. 223).

Abel Sierra Madero afirma que el Congreso de Educación y Cultura, realizado en La Habana en el año 1971, no solo se pronunció en contra de la homosexualidad, sino que también abordó cómo debía enfrentarse la presencia de los homosexuales en el ámbito cultural y citando la "Declaración”

\footnotetext{
${ }^{12}$ Ambrosio Fornet afirma que los parametrados "a través de sus respectivos sindicatos y amparados por la ley de Justicia Laboral, llevaron sus apelaciones hasta el Tribunal Supremo y éste dictaminó que la "parametración" era una medida inconstitucional y que los reclamantes debían ser indemnizados” (2015, pp. 220-221). Sin embargo, no aclara si las víctimas obtuvieron alguna respuesta desde el punto de vista legal.
} 
del mencionado evento el investigador transcribe la siguiente conclusión: "se debe evitar que ostenten una representación artística de nuestro país en el extranjero personas cuya moral no responda al prestigio de nuestra Revolución." ${ }^{13}$

El procedimiento disciplinario que se aplicó en contra de Fabián podemos vincularlo con los planteamientos de Michel Foucault sobre el individuo a corregir o el incorregible. Según el teórico francés, lo que define al individuo a corregir es "que es incorregible" (2000a, p. 64) y al respecto señala que

El incorregible, en la medida misma que lo es, exige en torno de sí cierta cantidad de intervenciones específicas, de sobreintervenciones con respecto a las técnicas conocidas y familiares de domesticación y corrección, es decir, una nueva tecnología de recuperación, de sobrecorrección. De manera que, alrededor de este individuo a corregir, vemos dibujarse una especie de juego entre la incorregibilidad y la corregibilidad. (Foucault, 2000a, p. 64)

Para las autoridades revolucionarias, Fabián es un anormal, un apestado a quien es necesario disciplinar para encauzar su conducta con el propósito de que sea útil en la edificación de la nueva sociedad que está construyendo la Revolución, la que por cierto no le da cabida a las minorías sexuales. En consecuencia, la medida que se toma en contra de Fabián nos remite a lo que Foucault denomina "disciplinas", es decir, "métodos que permiten el control minucioso de las operaciones del cuerpo, que garantizan la sujeción constante de sus fuerzas y les imponen una relación de docilidad-utilidad." (2008, p. 159).

A través de la historia de Fabián, la novela evidencia que la nueva sociedad que está construyendo la Revolución es intolerante al excluir a los homosexuales. Este aspecto demuestra, además, la incongruencia que existe entre los planteamientos de Ernesto Che Guevara, uno de los líderes de la Revolución, y el ejercicio del poder, porque en su ensayo titulado "El socialismo y el hombre en Cuba" afirma que para la juventud "el trabajo es un premio en ciertos casos, un instrumento de educación, en otros, jamás un

${ }^{13}$ Citado por Abel Sierra Madero (2006, p. 198). 
castigo" (Guevara, 2015, p. 124). Fabián, cuyo proyecto de vida es convertirse en "un pianista famoso" (p. 104), por el contrario, es sancionado por su condición sexual y sufre intensamente al estar obligado a trabajar en un lugar desagradable e inhóspito como la fábrica.

La fábrica ${ }^{14}$ como pantónimo, en términos de Philippe Hamon, se describe mediante la relación pantónimo-nomenclatura. Específicamente el narrador recurre a un procedimiento típico de lo descriptivo que es la "lista de predicados" (1991, p. 142). En ella se representa a la fábrica como un lugar que "estaba lejos de la ciudad, en un polígono industrial. Era una zona árida, sin un arbolito, donde sólo había almacenes industriales, terraplenes polvorientos, camiones y enormes zonas llenas de contenedores" (p. 217). Sobre este espacio el narrador sentencia que era un lugar "insípido, hostil, inhumano" (p. 217). En consecuencia, las representaciones de la fábrica la ilustran como un lugar en que predomina lo adverso y desagradable. Los operadores tonales "insípido, hostil, inhumano" forman un campo semántico en que predomina lo adverso y desagradable. Efectivamente, los adjetivos están asociados a semas que reiteran una y otra vez lo inhóspito del lugar.

A través de las descripciones como espacio diegético, la fábrica en la novela pierde sus rasgos distintivos ligados con el trabajo, la producción y la rehabilitación. Se convierte en un espacio que es resemantizado, debido a que adquiere diversas connotaciones durante el desarrollo del acontecer textual como: infierno, transgresión y trampa. Estos nuevos atributos con que es representada nos remiten a los planteamientos teóricos de Janusz Slawinski, quien se refiere a los "sentidos añadidos" ya que el mundo representado "produce significados adicionales, que se construyen encima de las presentaciones espaciales" (1989, p. 16). En la novela se introduce un estrato de connotaciones nuevo en torno a la fábrica, aspecto que comentaremos a continuación.

La vinculación de la fábrica con el infierno ${ }^{15}$ está relacionada con una

\footnotetext{
${ }^{14}$ No es la primera vez que Pedro Juan Gutiérrez incluye una fábrica como espacio narrativo. De hecho, en Trilogía sucia de La Habana hay un relato denominado "El bobo de la fábrica” que está situado en una fábrica de zapatos ortopédicos. La narración está centrada en Juan, el bobo, quien era provocado por las trabajadoras para que exhibiera su miembro viril o se masturbara delante de ellas.

${ }^{15}$ Juan Eduardo Cirlot señala que el infierno tiene un valor mítico constante en la
} 
afirmación del protagonista, quien señala de manera explícita: "No sé qué hacer para salir de este infierno. A veces me dan ganas de meter el brazo en el caldero hirviente para que me den la baja" (pp. 192-193). De esta forma, la fábrica para el protagonista es un lugar de tormentos y padecimientos en el que se encuentra atrapado en contra de su voluntad. Asimismo, este espacio se representa con un elemento distintivo del infierno cristiano, como lo es el fuego porque hay "un caldero hirviente” (p. 193). Fabián pretendía, además, huir de "aquel horno sofocante y de los vapores asqueantes de la cocina. Tenía los brazos, el pellejo y la barriga despellejados y medio quemados" (p. 206). Desde otro punto de vista, la vida del protagonista se convierte en un infierno permanente, ya que es obligado a abandonar la música y empezar a trabajar en la sección de "Descuartizado y troceo" de la fábrica.

La fábrica se convierte en un espacio de subversión, porque pese al férreo control que existe al interior de este espacio ocurren diversas transgresiones relacionadas con encuentros sexuales entre los trabajadores y entre Fabián y Antonio, "un negro ya mayor, de cuarenta o cincuenta años quizás pero alto, fuerte y fibroso, con cara de maleante y buscapleitos" (p. 207). De esta forma, los individuos infringen la legalidad surgiendo así la resistencia al poder. Este aspecto también se vincula con los planteamientos teóricos de Michel Foucault, quien afirma que el poder es "lo que dice no" y el enfrentamiento con el poder concebido de esta forma aparece como transgresión (Foucault, 200ob, p. 82). Plantea, además, que las relaciones de poder son intrínsecas a otros tipos de relación: de producción, de alianza, de familia, de sexualidad, y asevera que "no hay relaciones de poder sin resistencias, que éstas son tanto o más eficaces en cuanto se forman en el lugar exacto en que se ejercen las relaciones de poder" (Foucault, 200ob, p. 82).

Todas las representaciones de estas prácticas sexuales están singularizadas por diálogos y descripciones en las que predomina lo soez. Los siguientes ejemplos dan cuenta de este aspecto:

cultura humana y entre sus rasgos distintivos destaca que es concebido como "una forma de subvida y como un lugar de tormentos.” (1992, p. 251). Explica, además, que entre las expresiones iconográficas del infierno se encuentran el fuego, instrumentos de tortura y monstruos. 
Al tercer día de estar allí, el negro lo siguió en un momento en que él fue al baño a orinar. Se puso a su lado, le enseñó el aparato ya erecto y lo empujó hacia un rincón donde había un inodoro sin descargar y una pequeña puerta asquerosa. En aquellos baños siempre había poca o ninguna agua. Nadie los limpiaba, así que la suciedad y el olor a excrementos y orina era lo habitual. El negro lo agarró duro por los brazos y lo metió tras la puerta. Entonces lo obligó a agacharse y a metérsela en la boca [...] Antonio facilitaba las cosas. Untaba manteca de cerdo, abundante, y así, fácilmente, logró su objetivo. Fabián se quedó unos días con un gran dolor. (p. 208)

Tenía la espalda lacerada por las mordidas muy fuertes que Antonio le daba, sobre todo cuando tenía sus orgasmos salvajes. Antonio siempre sudado, con un olor terrible a sudor rancio, y un aliento cargado de alcohol, comida, suciedad y caries. Y encima en aquel lugar tan deprimente. Era evidente que lo único que excitaba a Antonio era la violencia y la furia. Mientras tenían sexo, Antonio siempre lo golpeaba por la cara, le estrujaba los huesos con sus manazas enormes y fuertes. Le daba duro y se erotizaba como una fiera salvaje. (p. 209)

En la novela, la fábrica también se encuentra ligada a la noción de trampa. En efecto, Fabián afirma que: "No sabía qué hacer ni cómo escapar. Lo habían metido en una trampa sucia y asqueante" (p. 210). Llama la atención que tanto la Revolución como la fábrica, que en el relato es representada como un lugar para corregir determinadas conductas, estén vinculadas a la idea de engaño y farsa. En este sentido, la novela refuerza la idea que la sociedad cubana se construyó con "trampa” y que uno de sus lugares de rehabilitación mediante el trabajo funcionen como tal. La fábrica, por lo tanto, sería otro engaño debido a que es una imposición de las autoridades revolucionarias y no cumple con el objetivo de rehabilitar y corregir las conductas de quienes escapaban de los requisitos del hombre nuevo.

Fabián, el protagonista, siente aversión en contra de los trabajadores de la fábrica y se pregunta: “¿De dónde salía tanta gente vulgar y grosera? En la calle no se veía gente así. Es como si los hubieran concentrado a todos en aquella fábrica” (pp. 216-217). Por tal razón, no tiene nada en común con ellos ni existe ningún tipo de vínculo. La descripción que hace de los obreros es bastante crítica porque los califica como zombis, siervos de la gleba y muñecos de cuerda:

Intentó buscar puntos de contacto. Algo que lo uniera a toda aquella 
masa amorfa de gente inculta, zombis que trabajan ocho horas al día repitiendo los mismos gestos, por un salario miserable que no les alcanza para nada. No piensan, no analizan, no saben pensar. Y ahí están como los siervos de la gleba en tiempos feudales. Simples muñecos de cuerda (pp. 217-218) ${ }^{16}$

La representación de los trabajadores se desarrolla a través de la inserción de una lista, en términos de Hamon, y contiene aspectos relevantes. En primer lugar, los representa como "masa amorfa de gente inculta”, en oposición a Fabián, quien es un joven educado y avezado en música. Contraste que pone de manifiesto una distancia insalvable entre el protagonista y el resto de los trabajadores. En segundo lugar, la alusión a los zombis da cuenta de que los obreros son “cadáveres", es decir, que los presenta como muertos vivientes. En tercer lugar, la vinculación con los siervos de la gleba está relacionada con una condición casi de esclavitud porque en la Edad Media debían servir a un determinado señor feudal y carecían de garantías legales que los protegieran. De esta forma, se insinúa que algunos de los trabajadores de la sociedad revolucionaria están en las idénticas condiciones a las del Medioevo. Y, por último, la caracterización de los trabajadores como muñecos de cuerda se conecta con la idea de autómatas.

\section{La fábrica según Pedro Juan}

La narración de Pedro Juan aporta aspectos relevantes en relación a la descripción de la fábrica, complementando los rasgos distintivos de este espacio debido a que Pedro Juan también es enviado a trabajar a la misma fábrica de carne enlatada, lugar en que se reencuentra con Fabián, con quien había sido compañero de curso durante la educación secundaria.

El espacio "nunca es indiferente para el personaje" (Garrido, 1996 p. 211) y en el caso de Pedro Juan es visto desde la perspectiva de rebeldía que lo caracteriza. Por tal razón afirma que el poder se ejerce de forma autoritaria y represiva, porque si alguien no trabajaba era detenido por lacra social y era destinado a las UMAP, Unidades de Militares de Ayuda a

\footnotetext{
${ }^{16}$ Los énfasis son nuestros.
} 
la Producción. A estos lugares eran enviados los vagos, los religiosos y los homosexuales, es decir, aquellos sujetos que se alejan del ideal del joven revolucionario:

A trabajar como un burro. Estabas preso pero al mismo tiempo estabas en un limbo legal, porque no te habían hecho un juicio. No había acusación ni condena. Si eras vago, maricón o religioso, te encerraban allí para que te rehabilitaras a través del trabajo. Trabajo y clases de marxismo durante unos cuantos años. Hasta que firmaras un papel asegurando que ya habías cambiado y por tanto no serías de nuevo vago. O maricón o religioso, según por lo que te hubieran encerrado. (p. 153)

Pedro Juan, el personaje, relata que en abril de 1971 se realizó el Primer Congreso de Educación y Cultura en el que se establecen los siguientes principios que determinarán más aún la exclusión de los homosexuales de la Revolución:

Los medios culturales no pueden servir de marco a la proliferación de falsos intelectuales que pretenden convertir el esnobismo, la extravagancia y el homosexualismo y demás aberraciones sociales, en expresión del arte revolucionario, alejados de las masas y del espíritu de nuestra Revolución. (p. 153)

La fábrica como pantónimo es representada a través de una nomenclatura que está a cargo de Pedro Juan, el otro personaje del relato. Philippe Hamon afirma que una de las formas más cómodas de hacer la inserción de una nomenclatura es la de delegar la declinación en un personaje que asume con su mirada esta declinación. De esta forma, "el paradigma de los objetos, de las partes, de las calidades constitutivos del objeto que va a describirse se convertirá en espectáculo, vista, escena, cuadro” (1991, p. 186).

En la primera descripción de la fábrica que hace Pedro Juan señala que este lugar "era una enlatadora enorme. Sobre todo de carne de cerdo" (p. 155). Luego se introducen otras representaciones que están singularizadas por la crudeza con que se describe la matanza de los animales y el sufrimiento que experimentan:

Cada día mataban a cientos de cerdos. No sé cuántos. Los metían en camiones desde las granjas y los metían en unos corrales enormes. Por 
la mañana temprano los hacían pasar en grupos de diez a un corral más pequeño, al fondo de la nave principal. Entonces un tipo agarraba un trozo de cabilla de acero, bien gruesa, se metía dentro del corral, y asestaba un solo golpe brutal en el cráneo del cerdo que estuviera más cerca. $\mathrm{Al}$ animal le brotaba la masa encefálica gelatinosa y una cantidad enorme de sangre por aquella herida, metía un berrido horrible y caía al piso temblando, con los estertores de la muerte. iPánico! Los cerdos restantes se aterraban. Reculaban hacia el fondo del corral, se encaramaban chillando unos sobre otros. Y se cagaban y meaban de miedo. Era todo un espectáculo. Sadismo puro. Se les salía toda la mierda y se cagaban unos encima de los otros, chillando sin parar. El verdugo ahora debía cuidarse porque los animales se defendían a dentelladas, furiosos. Y le atacaban. Pero el hombre era hábil y seguía matando rápido, uno tras otro. Les partía el cráneo de un solo golpe. Era un experto en asesinar cerdos (p. 155)

La descripción de una de las secciones de la fábrica, que es bastante gráfica y explícita, tiene el propósito de ilustrar este espacio como un lugar infernal, violento e inhóspito mediante la representación de la matanza de los animales en la que se menciona cómo los van reduciendo a medida que destruyen sus cuerpos. Por tal razón se hace referencia a la masa encefálica, la sangre y todo el sufrimiento que esto implica para los animales generando una escena monstruosa y aberrante.

Pedro Juan relata que todas las mañanas pasa por el matadero, otro espacio de la fábrica, a observar "el show sanguinario" (p. 156) que se desarrolla todos los días. Los trabajadores denominan al matadero como "Infierno" y al carnicero lo llaman "Diablo".

Me envicié a ir todas las mañanas al matadero a pasar un rato observando el show sanguinario. Los que trabajaban allí ya me conocían. Entre ellos le llamaban el Infierno. Y al carnicero le llamaban el Diablo. El tipo se reía, orgulloso. Trabajar allí era muy duro porque tenían que caminar sobre la mierda, embarrarse de mierda y sangre. Todos los trabajos eran duros. Para el descuartizado también había que estar fuerte y no tener estómago, pero el Infierno era lo peor. Ellos se reían. Era gente bruta. Y creo que les gustaba. Lo disfrutaban. Se embrutecían más cada día. Siempre me hacía una pregunta mientras los miraba actuar con tanto gusto y habilidad: si fueran seres humanos en lugar de cerdos, ¿̇los matarían también de un modo tan brutal y frío? Creo que sí. Funcionaban como autómatas (pp. 156-157) 
A través de referencias cristianas (Infierno y Diablo) el narrador describe el matadero, otro espacio de la fábrica. Este lugar también es retratado en torno a los desperdicios y la sangre que abundan en este sector. Estos elementos contribuyen, sin duda, a evidenciar un ambiente desagradable y repugnante e ilustran las condiciones en que tenían que trabajar quienes tenían que cumplir con las órdenes emanadas por parte de las autoridades.

Pedro Juan define a los trabajadores como "gente bruta", incluso afirma que "disfrutan la matanza de los animales" y está convencido que "si tuvieran que hacer lo mismo con seres humanos lo harían igual porque funcionan como autómatas.” Esta representación de los obreros está centrada en caracterizarlos como brutos y autómatas y coincide plenamente con la que hace Fabián, quien los califica como gente inculta, zombis, siervos de la gleba y muñecos de cuerda.

A través del desarrollo del acontecer textual, la fábrica como espacio adquiere otras connotaciones relevantes. En primer lugar, evidencia la corrupción del poder y en segundo lugar es un espacio de transgresión. La corrupción está relacionada con quienes detentan el poder al interior de la fábrica, vale decir, los jefes:

Los jefes eran unos oportunistas miserables y se aprovechaban de sus cargos. No tenían escrúpulos. Robaban todo lo que podían, sin ocultarse demasiado. Actuaban como si tuvieran derecho a robar. Algunos habían construido estupendas casas robando materiales de allí. Y después hacían reuniones donde ponían himnos y banderas y se repartían medallas y honores y certificados de trabajadores vanguardias. Y premios y más premios. Una obra de teatro. Nunca había visto tanta hipocresía. Vivíamos inmersos en una obra del teatro del absurdo. (pp. 157-158)17

El romanticismo me llevó a creer todo lo que había leído en los libros. Y aquello era todo lo contrario de lo que yo concebía como el comunismo. Para mí yo era un comunista perfecto y aquella gente unos delincuentes. Pero en la vida real era todo lo contrario: ellos eran los comunistas, con sus carnets y sus historiales heroicos de servicio a la patria, y yo una especie de microbio con graves desviaciones ideológicas. Los jefes no me miraban, no me dirigían la palabra ni el saludo, y cuando tenían que ordenarme algo lo hacían mediante un memorándum escrito. Querían

\footnotetext{
${ }^{17}$ Los énfasis son nuestros.
} 
que yo sintiera el desprecio que me tenían por no participar en sus chanchullos y por ser un bicho raro. (p. 159) $)^{18}$

El retrato de los jefes está asociado a una nomenclatura en que los operadores tonales forman un campo semántico que devela rasgos vinculados a una carencia de ética absoluta: “oportunistas”, “delincuentes”, inescrupulosos, aprovechadores, hipócritas.

La corrupción de quienes tienen el poder en los lugares de trabajo se opone radicalmente a los planteamientos que Ernesto Che Guevara expuso en "El socialismo y el hombre en Cuba”, porque según su ideología: "El Partido es una organización de vanguardia. Los mejores trabajadores son propuestos por sus compañeros para integrarlo" (Guevara, 2015, p. 124). En este caso, por el contrario, se muestra que los jefes de la fábrica carecen de la ética necesaria para premiar a los mejores trabajadores ya que ellos sólo se dedicaban a robar, pero seguían engañando en reuniones que eran montajes de un espectáculo sin sentido. Incluso, Pedro Juan afirma que los jefes lo desprecian por no participar en sus "chanchullos”, es decir, en actividades ilícitas de las que sacaban provecho.

Así, los ideales revolucionarios quedan relegados sólo al plano teórico porque en la práctica todo era una farsa de la que sacaban provecho quienes tuvieran algo de poder. En este sentido, comprobamos que la fábrica representada en la novela podría denominarse "anti-fábrica" debido a que no posee los rasgos distintivos que Michel Foucault señala sobre este tipo de lugares de disciplinamiento ${ }^{19}$ ni tampoco cumple el objetivo de rehabilitar a quienes eran considerados lacras sociales en el contexto revolucionario. El análisis evidencia que en la fábrica existe, por el contrario, corrupción, abusos de poder y robos. ${ }^{20}$

Además, la alusión al teatro del absurdo es significativa debido a que esta manifestación artística está sustentada, según Patrice Pavis, en los

${ }^{18}$ Los énfasis son nuestros.

${ }^{19}$ El teórico francés afirma que se trata de obtener de las fuerzas de producción, "el máximo de ventajas y de neutralizar sus inconvenientes (robos, interrupciones del trabajo, agitaciones y “cábalas”); de proteger los materiales y herramientas y de dominar las fuerzas de trabajo" (2008, p. 165).

${ }^{20}$ En el relato "El bobo de la fábrica” de Trilogía sucia de La Habana también se hace referencia explícita a este aspecto. Luisa, pareja de Pedro Juan, afirma que en la fábrica "todos roban a dos manos empezando por los jefes" (2012, p. 199). 
postulados filosóficos de Sartre y Camus, quienes "establecieron un retrato desilusionado de un mundo destruido y desgarrado por los conflictos y las ideologías" y señala que este tipo de teatro "centró la fábula en los problemas de la comunicación.” (Pavis, 1998, p. 20). En este sentido, Pedro Juan al comentar, con decepción y desengaño, que vivían inmersos en un teatro del absurdo refuerza el carácter falso e irreal que poseía la Revolución debido a los permanentes abusos de poder por parte de las autoridades que están a cargo de la fábrica

Los individuos infringen, quebrantan la legalidad surgiendo así la resistencia al poder. La transgresión se relaciona con las prácticas sexuales que se llevan a cabo al interior de la fábrica, la cual poseía un lugar al que los trabajadores le decían "El templadero ${ }^{21}$ ". En este espacio amplio, sucio, hediondo, que servía como depósito de desperdicios, siempre se desarrollaban encuentros sexuales:

Siempre había gente templando. De pie, claro. Era la única postura posible en medio de aquel lugar tan asqueroso. Las mujeres se inclinaban hacia adelante, y los hombres penetrándolas por detrás. Las mujeres gritaban desaforadas. Apresuradas. Unos minutos. Y ya. Después cada uno se iba por su rumbo. Y ya había otras parejas por allí. Por supuesto, muchos hombres pasaban horas y horas paseando, de voyeurs, masturbándose. El intercambio era normal. Se daba por descontado que a los voyeurs les gustaba enseñar sus espléndidos aparatos, y las parejas se calentaban más mirando a los pajeros. Era la regla del juego. Y todos felices. En ocasiones intercambiaban los papeles. El pajero iba con la mujer y el otro se apartaba un rato y se ponía a mirar y a masturbarse. Fueron precursores de los swingers. $\mathrm{O}$ al revés: dignos descendientes de la horda salvaje en pleno comunismo primitivo. (pp. 160-161)

En la fábrica, el sexo se convierte en una forma de subversión individual al poder que regula y controla todos los ámbitos de la sociedad representada en la narración. Este espacio es resemantizado en el relato, ya que pierde sus rasgos distintivos ligados al trabajo y la corrección. Los trabajadores de la fábrica, a quienes se pretendía rehabilitar a través del trabajo, inte-

${ }^{21}$ Según el Diccionario de la Real Academia Española, la palabra "templar" significa en Cuba: "Realizar el coito". 
rrumpen la jornada laboral con sus encuentros sexuales. Estos desacatos se oponen de manera radical a la sociedad normativa e ideologizada que pretende construir la Revolución.

\section{A modo de conclusión}

Fabián y el caos puede ser leída como una novela de denuncia política debido a que establece que la sociedad cubana construida por la Revolución se hizo con trampa. En este sentido, presenta una visión crítica de este hecho histórico ilustrando mediante la descripción de la fábrica el abuso y la corrupción del poder en los centros de disciplinamiento y trabajo, erosionando así la historia oficial.

El análisis evidencia que el espacio diegético es una categoría narrativa que contiene aspectos relevantes en torno a los que se despliega la ideología, la ética y la estética del relato. La narración se desarrolla a través de estética realista con un estilo predominantemente descriptivo, situando al lector en un periodo histórico complejo al exponer la tensa relación que se estableció entre Revolución y homosexualidad, dando cuenta de la marginación y exclusión de que fueron objeto los homosexuales en la primera década de la radical transformación que vivió Cuba. Revela, además, los procedimientos que desde los ejes de poder se tomaron en contra de los homosexuales y de aquellos que fueron considerados "lacras sociales", porque todos aquellos que no fueran revolucionarios y heterosexuales eran discriminados. Así, la novela ilustra, a través de la historia de Fabián y Pedro Juan, lo que ocurría a quienes se apartaran del modelo del hombre nuevo.

El relato muestra el fracaso del procedimiento denominado "depuración” o "parametración”, pues el lugar que se supone iba a permitir corregir determinados tipos de conducta consideradas inapropiadas en el nuevo orden revolucionario es otra trampa, al igual que la Revolución. De hecho, Fabián no deja de ser homosexual y Pedro Juan tampoco deja de lado su búsqueda del placer y los excesos. Desde el punto de vista ético rescata la figura del homosexual develando su encuentro con un poder que pretende amoldarlo a sus rígidos estándares normativos.

En la novela el espacio diegético es representado en torno a un pantónimo y una nomenclatura que básicamente está centrada en una lista de 
predicados que describen, delinean y retratan la fábrica y el contexto en que se van desarrollando las acciones del relato. Dentro de la lista de predicados cobran especial relevancia los operadores tonales que constituyen los puntos de articulación entre los niveles denotativo e ideológico de la descripción. A través de ellos se forma un campo semántico que evidencia y refuerza aún más la ideología que subyace en la novela. Además, en los enunciados descriptivos se despliegan los sentidos añadidos que aportan significados adicionales creando nuevas connotaciones resemantizando los espacios y objetos representados.

\section{Referencias bibliográficas}

Álvarez, Inmaculada. (2003). El discurso sexual como valor de identidad nacional cubano. Revista de Humanidades (Tecnológico de Monterrey), (14), 13-36.

Arenas, Reinaldo. (2010). Antes que anochezca. Buenos Aires: Tusquets Editores.

Barthes, Roland. (1987). "El efecto realidad”. En El susurro del lenguaje. Más allá de la palabra y la escritura (pp. 179-187). Barcelona: Paidós Comunicación.

Castro Ruz, Fidel. (1963). Discurso pronunciado por el comandante Fidel Castro Ruz, Primer Ministro del Gobierno Revolucionario de Cuba, en la Clausura del Acto para conmemorar el VI aniversario del asalto al Palacio Presidencial, celebrado en la escalinata de la Universidad de La Habana, el 13 de marzo de 1963. (Departamento de Versiones Taquigráficas del Gobierno Revolucionario). Recuperado de http://www.cuba. cu/gobierno/discursos/1963/esp/f130363e.html

Cirlot, Juan Eduardo. (1992). Diccionario de símbolos. Madrid: Siruela.

Contardo, Óscar. (2012). Raro. Una historia gay de Chile. Santiago: Planeta Chilena S. A.

Fornet, Ambrosio. (2015). El Quinquenio Gris: Revisitando el término. En Antología del pensamiento crítico cubano contemporáneo (pp. 207-225). Buenos Aires: CLACSO. biblioteca.clacso.edu.ar/clacso/ se/20151026o93519/AntologiaCuba. 
Foucault, Michel. (2000) (a). Los anormales. Buenos Aires: Fondo de Cultura Económica de Argentina, S. A. . (2000) (b). Un diálogo sobre el poder y otras conversaciones. Madrid: Alianza Editorial. . (2008). Vigilar y castigar. El nacimiento de la prisión. Argentina: Siglo Veintiuno Editores.

Fudacz, Jaime. (2012). "Tratar de decir lo que la gente no quiere oír". Una entrevista a Pedro Juan Gutiérrez. Revista Mester (41), 65-75. Recuperado de http://escholarship.org/uc/item/osk16ob9

Garrido Domínguez, Antonio. (1996). El texto narrativo. Madrid: Editorial Síntesis S. A.

Guevara, Ernesto (Che). (2015). "El socialismo y el hombre en Cuba". En Antología del pensamiento crítico cubano contemporáneo (pp. 113127). Buenos Aires: CLACSO.

Gutiérrez, Pedro Juan. (2001). "Verdad y mentira en la literatura." Recuperado de http://www.pedrojuangutierrez.com/Ensayos_ensayos_PJ_ Verdad\%20y\%2omentira.htm . (2006). El nido de la serpiente. Memorias del hijo del heladero. Barcelona: Anagrama. (2012). Trilogía sucia de La Habana. Barcelona: Anagrama. . (2015). Fabián y el caos. Barcelona: Anagrama.

Hamon, Philippe. (1991). Introducción al análisis de lo descriptivo. Buenos Aires: Edicial.

Hola Chamy, Constanza. 2015, 25 de octubre. "El ideal revolucionario no ha fracasado completamente, pero está en evolución." Entrevista a Pedro Juan Gutiérrez." BBCMundo. Recuperado de http://www.bbc.com/ mundo/noticias/2015/10/151025_hay_festival_entrevista_cuba_pedro_juan_gutierrez.

Lira Saade, Carmen. 2010, 31 de agosto. Entrevista a Fidel Castro: "Soy el responsable de la persecución a homosexuales que hubo en Cuba: Fidel Castro". Diario La Jornada. Recuperado de http://www.jornada.unam. $\mathrm{mx} / 2010 / 08 / 31 /$ mundo/o26e1mun

Néspolo, Matías. 2015, 29 de septiembre. Juan Gutiérrez: ' Para ser cubano hay que ser valiente'. El Mundo. Recuperado de http://www.elmundo. es./cultura/56oac60626e3e2e458b45ao. htlm. 
Olivares Baró, Carlos. 2015, 3 de noviembre. Entrevista con Pedro Juan Gutiérrez: "La literatura es lo único que puede profundizar en las zonas oscuras del ser humano." Recuperado de http://www.cubaencuentro.com/entrevistas/articulos/entrevista-con-pedro-juan-gutierrez-323985

Pavis, Patrice. (1998). Diccionario del teatro. Dramaturgia, estética, semiología. Barcelona: Paidós.

Pimentel, Luz Aurora. (2001). El espacio de la ficción. Ficciones espaciales. La representación del espacio en los textos narrativos. México: Siglo Veintiuno Editores.

Sierra Madero, Abel. (2006). Del otro lado del espejo. La sexualidad en la construcción de la nación cubana. La Habana: Fondo Editorial Casa de Las Américas.

. (2016). "El trabajo os hará hombres": Masculinización nacional, trabajo forzado y control social en Cuba durante los años sesenta. En Cuban Studies, (44), 309-349.

Slawinski, Janusz. (1989). "El espacio en la literatura: distinciones elementales y evidencias introductorias", en Revista Criterios (La Habana), 265-287. Recuperado de http://www.criterios.es/pdf/slawinskiespaciolit.pdf 